\title{
LA CONSTRUCCIÓN DE CEMENTERIOS EXTRAMUROS: UN ASPECTO DE LA LUCHA CONTRA LA MORTALIDAD EN EL ANTIGUO RÉGIMEN
}

\author{
José Luis SANTONJA
}

\begin{abstract}
Resumen
La cuestión del enterramiento en el interior de los templos fue un tema planteado a lo largo del Setecientos, tanto por la Iglesia como por el Estado. En 1784 Carlos III dispuso que a partir de entonces los cadáveres no fueran inhumados en los templos. Sin embargo la aplicación de esta orden se dilató al menos hasta la primera década del siglo XIX, tanto por las limitaciones presupuestarias de las administraciones parroquiales como por las resistencias de los feligreses.
\end{abstract}

\begin{abstract}
The question about the buriel in the chapels was a subject discused both by the Church and the State throughout the XVIII Century. In 1784 Charles III ordered that from then the bodies could not be intermed in the churches. However the implication of this order was delayed at least until the first decade of the XIX Century, not only because of the economical implications for the parochial administrations but because the resistance of the parishioners.
\end{abstract}

«Es indubitable que en muchas de las Iglesias de nuestra Diócesis se hace insufrible el mal olor que despiden los cadáveres, lo que retrae á muchas gentes de la concurrencia á sus Parroquias, y les precisa irse á otros templos, en los que no son tan frequïentes los entierros» (Fray Joaquín Company, Arzobispo de Valencia, A todos nuestros Curas Párrocos y demás Diocescinos, 1806).

La cuestión del enterramiento en el interior de los templos fue un tema planteado a lo largo del Setecientos; en un primer momento fue la Iglesia la que estuvo a favor de limitar estos enterramientos. La perspectiva del Estado se planteó desde el punto de vista higiénico. Si durante todo el siglo XVIII se sucedieron políticas de prevención para desterrar el riesgo de epidemias, con el control del tráfico portuario, la ejecución de planes generales de alcantarillado y la retirada de desperdicios de las 
vías públicas, el enterramiento en el interior de las poblaciones continuaba constituyendo un evidente riesgo para la salud pública. La hora de abordar esta cuestión de forma definitiva aconteció «con ocasion de la epidemia experimentada en la Villa de Pasage, Provincia de Gupúzcoa, el año de mil setecientos ochenta y uno, causada por el hedor intolerable que se sentia en la Iglesia Parroquial de la multitud de cadáveres enterrados en ella». El 3 de agosto de 1784 una real orden dictada en este sentido por Carlos III disponía que a partir de entonces los cadáveres no fueran inhumados en las iglesias. Era una medida que venía a ser un reflejo inmediato de la prohibición francesa de 1776 , como indica Vovelle ${ }^{`}$ Tres años más tarde, en 1787 , esta medida fue ratificada por medio de una real cédula ${ }^{2}$. En ella se restringía el derecho de inhumación en los templos a los prelados, patronos y personas del estamento religioso que estipulaba el Ritual Romano y la Novísima Recopilación (en concreto, la «ley 11 , tit. 13 de la part. I») ${ }^{3}$. Se disponía la construcción improrrogable de «los Cenenterios fuera de las Poblaciones siempre que no hubiere dificultad invencible ó grandes anchuras dentro de ellas, en sitios ventilados é inmediatos á las Parroquias, y distantes de las casas de los vecinos», aprovechándose para capillas de los mismos cementerios «las Hermitas que existan fuera de los Pueblos». Esta edificación se ejecutaría atendiendo al proyecto que en cada caso presentaran de común acuerdo el cura y el corregidor de la población respectiva.

Esta iniciativa oficial, tendente a mejorar las condiciones higiénicas de los vecindarios, chocaba con la cruda realidad. El mismo Diario de Valencia denunciaba en 1790 Ia insalubridad urbana; un redactor suyo afirmaba que «con quánta razón se llaman a las grandes ciudades sepulturas de la especie humana». Aquel mismo año el tribunal del repeso prohibía públicamente a todos los ciudadanos hacer sus necesidades en la calle, ya que atentaba contra el «aseo y policía pública (...) recato y decencia», y les recomendaba que en caso de urgencia y perentoriedad habían de buscarse lugares ocultos, como los portales de las casas. Además, se anunciaba la instauración de un nuevo sistema de recogida de animales muertos en el recinto de la ciudad, a través de las denuncias de los vecinos al tribunal, el cual tramitaría las órdenes oportunas al perrero ${ }^{-1}$.

La orden de construcción de cementerios extramuros se dilató, además, de forma excesiva. Prácticamente antes de la llegada del siglo XIX no se había llevado a cabo ninguna edificación mortuoria de este tipo de forma generalizada. Las causas de este

1. Michel Vovelle, La mort et l'Occident de 1300 à nos jours, París: 1983, p. 425.

2. Archivo Municipal de Alcoi, Órdenes y veredas (1787-1790), reg. 3139; Real Cedula de S. M. y Señores del Consejo, en que por punto general se manda restablecer el uso de Cementerios ventilados para sepultar los Cadáveres de los Fieles, y que se observe la ley 11, tit. 13 de la Partida primera, que trala de los que podrán enterrarse en las Iglesias; con las adiciones y declaraciones que se expresan. Año 1787. En Madrid: En la Imprenta de Don Pedro Marin.

3. Novísima Recopilación, ley I, libro I, título III; «Restablecimiento de la Disciplina de la Iglesia en el uso y construeción de cimenterios según el Ritual Romano». Natividad Moreno. Colección de Reales Cédulas del Archivo Histórico Nacional, Madrid: 1977, I, 520, cédula $n^{\circ} 2.949$.

4. Vicent Lluís Salavert; Jorge Navarro, La sanitat municipal a Valencia (segles XIII-XIV), Valencia: edicions Altóns el Magnànim - Diputació Provincial de València, 1992 (col.lecció Politècnica, 48), p. $53-54$. 
retraso eran muy diversas, desde las limitaciones presupuestarias de las administraciones parroquiales hasta las resistencias de los feligreses para ser enterrados fuera del ámbito de los templos. El propio arzobispo de Valencia, Francisco Fabián y Fuero, hubo de dirigir una carta pastoral a los párrocos de su jurisdicción para darles a conocer las instrucciones contenidas en la real cédula de 1787 y animándolos para que llevaran a buen puerto, y a pesar de las resistencias, la beneficiosa obra que les encomendaba la Corona 5 .

Esta dilación provocó la constante emisión de órdenes y provisiones desde la Corte para que no se abandonase la construcción de los cementerios. En 1799 Carlos IV instó al Real Consejo a que «tomase en consideracion nuevamente este importantísimo asunto con respecto á Madrid, sin embargo de lo que estaba determinado generalmente por su augusto Padre en la Real Cédula de 3 de Abril de 1787, y se ocupase seriamente y con la mayor brevedad en proponer medios sencillos para establecer fuera de sus muros cementerios en que indistintamente se hubiesen de enterrar los cadáveres de todas clases de personas». En 1804, además, se recordó a todos los cabildos locales los perjuicios que ocasionaba la ausencia de cementerios en condiciones: «los funestos efectos que ha producido siempre el abuso de enterrar los cadáveres en las Iglesias, se han comprobado con mucha especialidad en los años próximos y en el presente, en que afligidas las mas de las Provincias del Reyno, y muy señaladamente las de las dos Castillas, con enfermedades malignas, han experimentado un lastimoso estrago». Por esta razón había de ejecutarse las obras de forma inmediata y no esperar a que se desatara cualquier epidemia, «pues han sido muchos los Pueblos que, viendo fomentarse rápidamente las enfermedades en su recinto, y no pudiendo dudar que llegarian á causar su total desolacion, si no adoptaban como una de las medidas mas esenciales la de suspender los enterramientos en las Iglesias, la han abrazado espontáneamente, disponiendo se hiciesen en parages ventilados y distantes de poblado». Esta excesiva urgencia había comportado dos efectos negativos: primero, que no había podido remediar «los males que habia causado ya el ayre infestado de las Iglesias» $\mathrm{y}$, en segundo lugar, no había podido observarse el correcto decoro en los enterramientos de los cadáveres «por no permitirlo la urgencia de las circunstancias, y la falta de disposiciones anticipadas». Se recordaba por tanto, y una vez más, la idoneidad de construir los cementerios fuera de los poblados, de acuerdo a una serie de recomendaciones: situarlos en lugares altos, alejados del vecindario y sin filtración de aguas.

Se adujo, además de las razones higiénico-sanitarias, los motivos espirituales que favorecían la creación de cementerios extramuros. Carlos IV, en su «religioso corazon», había advertido que los templos, por «respeto y veneracion debidos á la Casa de Dios», habían de ser los lugares más puros, pero que por su uso como osarios, «se

5. Biblioteca Histórica de la Universitat de València: [Carta pastoral del Arzobispo Fabián y Fuero a los párrocos de su diócesis sobre la $R$. Orden de 20 abril para la erección de cementerios], impr., Valencia: s.n., 1787.

6. Circulares del 26-IV-1804 y 28-VII-1804, citadas por Natividad Moreno, Colección de Reales Cédulas del Archivo Histórico Nacional, II, $\mathrm{n}^{\circ} 4.122$ y 4.145. M. Milanesi: «Tra la vita e la morte. Religione, cultura popolare e medicina nella seconda metà del 1700», en Quaderni storici, no 50, 1982. p. 615-620. 
miran convertidos por un trastorno lamentable de ideas en unos depósitos de podredumbre y corrupcion», costumbre extendidísima en el país y que no había «bastado á evitar esta profanacion, ni las repetidas sanciones canónicas que la han prohibido (...) ni el ver que es causa de que, retrayéndose muchos de los fieles de freqüentar los Templos, que son los lugares destinados especialísimamente para sus ruegos, se debiliten sucesivamente los sentimientos y actos de piedad y religion, ó de que á lo menos prefieran la concurrencia á las Iglesias en que son menos comunes los enterramientos, dexando casi abandonadas las Parroquiales, con grave ofensa de la disciplina eclesiástica, y mengua de la instruccion que deben recibir de sus Pastores».

En ese mismo año de 1804 fueron designados una serie de comisionados para atender la construcción de cementerios en todo el país. Para el arzobispado de Valencia salió elegido Manuel del Pozo que rápidamente se puso al servicio de fray Joaquín Company, por entonces titular de la archidiócesis valentina. Este prelado, advertidas las resistencias que de tipo espiritual ofrecían los feligreses de su diócesis, les dirigió una pastoral en mayo de 1806. En ella se hacía eco de la opinión del monarca sobre que «se hace insufrible el mal olor que despiden los cadáveres, lo que retrae á muchas gentes de la concurrencia á sus Parroquias, y les precisa irse á otros templos, en los que no son tan freqüentes los entierros». Y es que, en efecto, el templo, «es un lugar destinado para ofrecer á nuestro Dios y Señor los Sacrificios santos y puros: en donde nos congregamos para unir nuestros votos, é implorar la proteccion del Cielo», y por ello «debe estar limpio, aseado, y muy distante de toda corrupcion». Para el arzobispo Company esta costumbre de enterrarse en los templos surgió «en nuestra España en los Siglos doce y trece», cuando «empezaron á verse algunas exenciones en los Patronos de las Iglesias, y Personas que morian con la opinion de singular virtud». Estas distinciones se fueron multiplicando hasta el extremo de ser enterrados todos los feligreses difuntos en los templos, «convirtiendo las Iglesias en unos verdaderos cementerios». Nadie se acordaría de las medidas promulgadas por la Corona sino por «algun incidente calamitoso (...) como sucedió el año quatro de este siglo, en que la Epidemia que causó tantos estragos en varios Pueblos de la Península, dió motivo para expedir el Consejo la órden que antecede, y otras que estrechan mas que la Cédula expedida por nuestro Católico Monarca Don Cárlos Tercero, de gloriosa memoria, su fecha en tres de Abril de 1787». La falta de previsión en la apertura de modernos cementerios había ocasionado «ver amontonar los cadáveres en una misma zanja, substituyendo esta providencia espantosa á la de los cementerios bien ordenados con tiempo, que hacen menos formidable esta desgracia». El propio arzobispo reconocía que «la mayor parte de los Pueblos de nuestro Arzobispado tienen ya construidos sus cementerios, y sola la escasez de caudales en algunos ha podido retardar un tanto su construccion». También citaba que «los motivos que han tenido los Fieles para sostener su empeño de enterrarse en las Iglesias, ha sido el de excitar la memoria de los difuntos, para que roguemos por ellos, y honrar aquellos cadáveres que por el artículo de la resurreccion creemos que algun dia seran glorificados, y Ciudadanos de la Jerusalen celeste», pero que este culto hacia los muertos había de quedar garantizado por las «sabias» disposiciones del gobierno, esto es, con la erección de capillas anexas a los cementerios, que «sean capaces, y de- 
centes para la celebracion del Santo Sacrificio de la Misa», la ubicación de las sepulturas del clero junto a estas capillas y, respecto al estamento nobiliar, «para no confundir la Nobleza los huesos de sus Familias con lo restante de la Plebe, se les permite hacer sus Panteones para su entierro». Además no se mudaría en ningún caso el tradicional ceremonial mortuorio: «la pompa funeral establecida por las Sinodales, en nada se altera, porque los cuerpos serán conducidos á sus Parroquias como hasta ahora, se celebrarán todos los oficios de Sepultura, y solo se suspenderá el acto de entierro depositando el cadáver en una Capilla destinada á este efecto hasta entrada la noche (...) El repique de campanas, la vista de los cadáveres, y los demás aparatos fúnebres, dispertarán como hasta ahora la memoria de la muerte para rogar por los difuntos».

En cuanto a la disposición física de los cementerios, «y para quitar el horror que pudiera ocasionar la reunion de tantos cadáveres, se procurará plantar árboles propios de aquel sitio, que sirvan de adorno con su frondosidad». En el caso de la ciudad de Valencia, Company afirmaba que «como este territorio está tan poblado, que hasta dos leguas de la Ciudad es continuo el vecindario, no es posible construir en despoblado el cementerio", por lo que había de precaverse a los vecinos inmediatos sobre cualquier corrupción y contagio, disponiéndose que en el futuro «se edificará otro si fuese necesario para conservar la pureza de los ayres». Esta medida supuso la desaparición de los cementerios de las parroquias de san Lorenzo, san Juan del Mercado, santa Catalina y san Martín, y del convento de san Francisco. Construidos de este modo los cementerios, «léjos de retraer á las Almas justas de aquel lugar sagrado, excitarán su devocion á visitarlos, y ofrecer en ellos sus votos á Dios nuestro Señor por los Difuntos, que descansan alli en paz, como lo hacian los Christianos de la primitiva Iglesia en las Catacumbas de los Mártires». En ellos «á un golpe de vista encontrarán lecciones saludables para despreciar lo vano, fantástico é ilusorio de este mundo, y aspirar solo á los bienes eternos». Por último el prelado encargaba a los párrocos que procurasen hacer «ver á sus respectivos Feligreses las utilidades que resultará á el Público de estos establecimientos pios...»?

\section{LA CONSTRUCCIÓN DEL CEMENTERIO EXTRAMUROS DE ALCOI ${ }^{8}$}

En la villa de Alcoi la costumbre de inhumar los cadáveres en el interior de los templos se desarrolló a mediados del siglo XVI, lo que de hecho fue algo general en todo el país, manteniéndose abierto no obstante el antiguo cementerio medieval ubicado a las puertas de la parroquia. En Alcoi y durante la primera mitad del siglo XVIII todavía se mantuvo en uso este antiguo cementerio medieval, ubicado delante

7. Nos D. Fr. Joaquín Company, por la Gracia de Dios y de la Santa Sede Apostólica, Arzobispo de Valencia,... A todos nuestros Curas Párrocos y demás Diocesanos, salud y paz en nuestro Señor Jesu-Christo, (1806, Mayo, 30. Valencia), s.l: s.n., s.a., impr., p. 6-13 (ejemplar facilitado al autor por D. Antonio Castelló Candela, de Alcoi).

8. Para la redacción de este capítulo nos hemos servido de los epígrafes dedicados al tema en nuestra tesis doctoral inédita, Iglesia y sociedad en una villa valenciana: Alcoi, 1300-1845, Universidad de Alicante, Departamento de Historia Medieval y Moderna, 1998, 3 v. 
de la iglesia parroquial de santa María, en el área que hoy ocupa la plazuela de la Virgen Maria". En él había fosas particulares y otras comunes, en las que se enterraba a los pobres y los restos que se sacaban al vaciar las fosas del interior de los templos. Según Ariès era obligatorio que los infantes que morían sin uso de razón fuesen sepultados fuera de los templos, pero esto era puramente teórico pues en Alcoi, desde luego, los niños, incluso recién nacidos, eran enterrados en las fosas propias de sus familiares, aunque estuviesen dentro de los templos ${ }^{10}$.

En el interior de las iglesias los difuntos eran enterrados en fosas propias de su parentela, en fosas comunes o en fosas propias de hermandades, cofradías o gremios. Tanto el clero parroquial como las distintas comunidades religiosas tenían instalado su propio osario en lugar privilegiado, cerca del presbiterio o en torno al altar mayor de su templo respectivo. Las fosas se situaban en prácticamente todas las iglesias de Alcoi: la parroquial de santa María y sus anexas (ermita de san Jorge y capilla de la cofradía de Nuestra Señora de la Asunción) y los templos conventuales de san Agustín, de san Francisco y del Santo Sepulcro. El de san Francisco, no obstante, quedó inhabilitado para este uso a partir de 1707 cuando su edificio fue volado en el transcurso del asedio borbónico y prácticamente no se abrió fosa alguna en él por lo menos hasta su consagración en 1753. Aparte de estos sepulcros particulares de cada familia o linaje, existían otros de uso más amplio, cuyos titulares eran cofradías, gremios o comunidades religiosas. En el templo parroquial de santa María el clero tenía su sepultura bajo el coro, delante del altar mayor; también tenían fosa en este templo los miembros de la cofradía de Nuestra Señora del Rosario, ubicada en la capilla de su advocación. En la iglesia del convento de san Agustín sus religiosos se enterraban cerca del altar mayor; los hermanos de la cofradía de Nuestra Señora de la Correa lo hacían en una fosa abierta en la capilla de su patrona y los maestros del gremio de herreros en la que tenían en la capilla de su patrón, san Eloy. En el templo del Santo Sepulcro sólo había un reducido número de tumbas de particulares y la fosa que servía para la comunidad de religiosas de este convento, situada junto al altar mayor.

Cada familia aspiraba a tener su tumba propia y su ubicación estaba en relación con su capacidad económica y posición social. Los lugares privilegiados para el establecimiento de sepulturas habían sido ocupados por los titulares respectivos de los templos (clero y comunidades religiosas) y en segundo lugar por el estamento superior de la localidad (clases de nobles, caballeros, generosos y ciudadanos), que se había reservado capillas o lugares próximos al altar mayor o a altares privilegiados, donde una sola misa podía redimir un alma del purgatorio ". El resto iría posesionándose del sitio libre que iba quedando en el área del templo ${ }^{12}$. En la iglesia parroquial

9. Ricard Bañó, Rutes històriques i monumentals d'Alcoi, Alcoi: Ajuntament - Centre de Professors, 1988, p. 28.

10. Philip Ariès, El hombre ante la muerte, Madrid: Taurus, 1987, p. 54-56.

11. Antonio Peñafiel Ramón, Testamento y buena muerte (Un estudio de mentalidades en la Murcia del siglo XVIII), Murcia: 1987, p. 137-140.

12. Philip Ariès, El hombre ante la muerte, p. 73-75. Antonio Eiras Roel: «Las élites urbanas de una ciudad tradicional: Santiago de Compostela a mediados del siglo XVIHl», en Actas de las II jornadas de metodología histórica aplicada, Santiago de Compostela: Universidad de Santiago, 1984, I, p. $127-$ 
los miembros de la clase de nobles, generosos y caballeros se enterraban en capillas propias o en fosas abiertas frente a un altar privilegiado. En la iglesia del convento de san Agustín lo hacían igualmente en capillas propias o cerca del altar mayor y en la del Santo Sepulcro también cerca de este altar. La segunda clase social, la de ciudadanos, mostraba idéntico comportamiento, ocupando capillas y lugares próximos al altar mayor y a los altares privilegiados. Por contra, el grupo de los artesanos presentaba ya unas notables diferencias frente a estas dos clases en cuanto a la distribución espacial de sus tumbas. En la parroquial se enterraban mayoritariamente en las zonas de acceso al templo, es decir, tras las puertas principales y laterales, y en menor número en capillas propias y junto a altares no privilegiados. En el templo de san Agustín la mayor parte ocupaba lugares cercanos a capillas y altares, pero pocos poseían capilla propia, como ocurría en el templo del Santo Sepulcro. Los labradores se asemejan bastante al comportamiento de los artesanos pero con la diferencia de ocupar menos capillas en general y situarse en sitios más comunes que los de éstos. En la iglesia parroquial la mayor parte tenía sus fosas cerca de capillas y altares no privilegiados; lo mismo ocurría en la iglesia de san Agustín pero en la del Santo Sepulcro la distribución todavía era menos significativa y casi todos ellos ocupaban lugares en medio del templo.

En el siglo XVIII las iglesias presentaban ya una total masificación de lugares de sepultura y en algunas de ellas, como la parroquial y la de san Agustín, resultaba imposible establecer nuevos sitios para tumbas. A pesar de ello existían mecanismos de transmisión para asignar nuevos sitios, pues los particulares podían ceder el derecho de sepultura o traspasarlo si no pensaban hacer uso de él, pero esto mismo también podía efectuarlo el clero. El medio para establecer nuevas familias era la incautación de las que habían caído en desuso. Para certificar esta situación en cada festividad de Todos los Santos el sacristán recorría, acompañado de un notario, todo el templo certificando las sepulturas que estaban iluminadas y las que no. Cuando transcurrían tres años consecutivos en que se apreciaba la falta de cuidado en una sepultura, se procedía a incautarla, vaciarla y establecerla a otro beneficiario. Este tipo de traspasos suponía en realidad una enajenación de lugar sagrado, lo cual, a todas luces, no podía jamás ser objeto de comercio. A pesar de ello, el clero lo disimulaba manteniendo la ficción de que no se percibía nada por este establecimiento sino sólo una limosna. Durante la segunda mitad del siglo XVIII los agustinos, por ejemplo, continuaron estableciendo sepulturas a base de expropiar las que caían en desuso. Los particulares, como hemos dicho, podían traspasar las fosas de las que eran titulares. Este traspaso podía efectuarse como venta del derecho de enterramiento, cesión, renuncia o incluso como admisión: la venta del derecho de sepultura se efectuaba con el anexo de las misas fundadas en ella; la cesión del derecho de sepultura se asemejaba a la simple venta con la salvedad de que el otorgante se reservaba el derecho de poder en-

128. Marion Reder Gadow, Morir en Málaga. Testamentos malagueños del siglo XVIII, Málaga: Universidad de Málaga, 1986, p. 91-98. A. Visceglia, «Corpo e sepoltura nei testamenti della nobilità napoletana (XVI-XVIII secolo)», en Quaderni storici, n 50, 1982, p. 598. Michel Vovelle, La mort et l'Occident de 1300 à nos jours, p. 351. 
terrarse en ella; la renuncia al derecho de sepultura se hacía cuando el titular se marchaba a residir a otro lugar; por último, la admisión suponía que el titular de la sepultura aceptaba otro usuario.

Los franciscanos, en contra de lo que hacian otras comunidades regulares, se negaron a que en su templo se abriesen fosas de titularidad particular. Sólo permitieron la apertura de una fosa destinada a los miembros de la cofradía del Cordón y a los hermanos de la tercera orden de seglares, ambas fundadas en dicho convento. Por tanto, todos los que quisieran ser sepultados en el templo de los recoletos tendrían que ser miembros de alguna de estas asociaciones; puede ser esto quizás una de las razones que expliquen la enorme afluencia de ingresos de hermanos que tuvo la tercera orden durante la segunda mitad del siglo XVIII.

Mientras tanto el viejo cementerio se deterioraba rápidamente a causa de su antigüedad pero sobre todo por el descuido que padecía puesto que, al construirse la nueva parroquia, se tenía previsto clausurarlo y abrir otro delante del nuevo templo parroquial. La degradación llegó a tal extremo que en 1757 el cabildo municipal dispuso que se abrieran fosas comunes dentro de la capilla de la cofradía de la Asunción, sita delante de este cementerio, al reconocerse que dicho camposanto se hallaba «sin cerco, entrándose en él los perros y demás animales y sacando [los huesos de los cadáveres] para roerlos fuera de dicho sitio» ${ }^{13}$.

En 1768 fue abierto al culto el nuevo templo parroquial. Pero en él quedó absolutamente prohibido abrir fosa alguna, al parecer siguiendo las instrucciones del Arzobispado. Para cementerio se habilitó el espacio que había delante del templo y se clausuró el antiguo camposanto. A pesar de todo, se construyeron dos criptas, una para albergar los cuerpos de los miembros de la cofradía del Rosario y otra para el clero, pero no se permitió ninguna otra excepción en este punto. Con la apertura del nuevo templo parroquial, los enterramientos sufrieron una gran redistribución al clausurarse tanto el antiguo cementerio como el anterior templo, lo que obligó a los titulares de fosas allí abiertas a buscarse otras en distintas iglesias. En 1770, en efecto, el ayuntamiento ordenó que no se enterrase a nadie más en la antigua parroquia, «por quanto haviéndose asolado varias sepulturas de la antigua Iglesia de esta villa, donde el clero continuamente ha prosiguido en dar tierra a los cadáveres, los que, con motivo de tal desolación, han causado un edor intolerable, bastante para enfermar y apestar al pueblo» ${ }^{14}$. La limitación de inhumaciones en la nueva parroquial de Alcoi fue un hecho completamente inusual a lo que se hacía en otros lugares de España y Francia, donde se produjo un trasvase de enterramientos desde las iglesias conventuales a las parroquias ${ }^{15}$. Lógicamente, en Alcoi los templos conventuales recibieron una

13. Archivo Municipal de Alcoi, Libro de cabildos, cabildo del 31-XII-1757, citado por Juan M. Dávila Linares, «El urbanismo y la ciudad de Alcoy en el siglo XVIII», en Reyista de Fiestas de Alcoi, Alcoi: Asociación de San Jorge, 1988, p. 155.

14. Archivo Municipal de Alcoi, Libro de cabildos 1762-1771, cabildo del 20-IX-1770, p. 810-811.

15. N. Lemaitre: «Histoire d'une marginalité: les testaments bretons aux XVIIIe. - XIXe. siècles (17501850)», en (Les) Actes notariés. Source de l'histoire sociale, XVle-XVIIle. siècles (Colloque de Strasbourg, 1978), París: P.U.F., 1979, p. 284. A. Valls Tur, Estudio documental del Archivo Municipal de Elche. Protocolos del Escribano Antonio Ceva (1783-1804), tesis de licenciatura inédita. Universidad 
inusitada demanda para establecer nuevas fosas. En el templo de san Agustín, que ya estaba saturado, se establecieron pocas; donde más enterramientos se produjeron con respecto a la primera mitad del siglo XVIII fue en la iglesia de san Mauro y san Francisco. Si bien los recoletos no habían permitido que los particulares abriesen fosas propias en su templo lo cierto es que la tercera orden de seculares, que sí contaba con una sepultura abierta en dicha iglesia, se convirtió en un coladero gracias al cual muchos lograron ser enterrados en el interior del templo. Esto explica, por una parte, la gran difusión que tuvo esta orden tercera y por otra la elevada demanda de enterramiento en la iglesia de los franciscanos que se produjo durante la segunda mitad del XVIII.

Mientras estuvo abierta la antigua parroquia y se consintieron los enterramientos en ella, los testadores pudieron elegir ser enterrados prácticamente en todos los templos que había abiertos en Alcoi. La demanda se centró sobre todo en los templos conventuales más que en la parroquia y sus anexas (la capilla de la cofradía de la Asunción y la ermita de San Jorge); esta predilección por los enterramientos en los conventos era, según la escuela francesa, un indicativo de la permanencia de una religiosidad barroca ${ }^{16}$. La proporción de los que eran sepultados en las iglesias conventuales de Alcoi era similar a otros lugares, como la Marsella estudiada por Vovelle. El templo de san Agustín era el que más demanda de enterramientos recogía en Alcoí hasta 1768. La cofradía del Rosario, instituida en la parroquia a finales del siglo XVI, fue la única autorizada a enterrar en el nuevo templo parroquial. Tenía dos fosas, una de caridad y otra para sus hermanos. Prácticamente se convirtió durante el siglo XVIII en una asociación para la preparación de la muerte, pues esta actividad, junto con el fomento del culto al rosario, era lo que más la destacaba según indican los testamentos. Por el contrario, la antigua cofradía de la Asunción, la primera que existió en Alcoi (fundada a fines del siglo XV) y que había sido erigida principalmente para ocuparse de los entierros y funerales de quienes no tenían posibilidades para ello, sufrió una gran decadencia. La capilla de la cofradía de la Asunción y la ermita de san Jorge eran lugares anexos a la parroquia en los que se permitía asimismo el enterramiento; pero, al tener dimensiones reducidas, los lugares de sepultura que acogían eran escasos. En la capilla de la Asunción se hallaba una fosa común y cinco de uso particular; en la ermita de San Jorge tan sólo dos, de título familiar.

La primera instrucción que llegó a Alcoi sobre la edificación de un cementerio extramuros fue la real cédula de 1787, aunque de momento el ayuntamiento no tomó iniciativa alguna puesto que hacía menos de dos décadas que se había abierto el nuevo cementerio parroquial. Pero la aparición de sucesivas epidemias obligó a que los regidores retomaran el asunto del cementerio extramuros. En el verano de 1800 llega-

de Alicante, Departamento de Historia Medieval y Moderna, I, p. 200. Michel Vovelle, Pieté baroque et déchristianisation en Provence au XVIIIe. siècle, París: P.U.F., 1978, p. 187.

16. Philip Ariès, El hombre ante la muerte, p. 76. Pierre Chaunu: «Un nouveau champ pour l'histoire sèrielle: le quantitatif au troisième niveau», en Histoire quantitative, histoire sérielle, Cahiers des Annales, $\mathrm{n}^{\circ}$ 37, París, 1978, p. 224. D. González Lopo: «La actitud ante la muerte en la Galicia occidental de los siglos XVII y XVIII», en Actas de las II jornadas de metodología histórica aplicada, II, p. 134. Michel Vovelle, Pieté baroque et déchristianisation en Provence, p. 185. 
ron noticias de que la fiebre amarilla se había propagado por el puerto de Cádiz y amenazaba extenderse por toda Andalucía. En Alcoi cundió la alarma en el mes de octubre; entonces el gobierno local impuso el tradicional aislamiento de la villa: guardias en las puertas de ingreso a la población, control de la llegada de forasteros, especialmente los que procedían de Andalucía, y orden de registro para todas las personas y mercaderías que entrasen en la villa, bajo la estricta supervisión del corregidor ${ }^{17}$. En el sur de España mientras tanto se extendía el contagio ante el fracaso o la ineficacia de las medidas adoptadas para controlar la epidemia. El polígrafo Blanco White relató en una de sus cartas la actuación del consejo municipal de Sevilla durante el verano de 1800. Para sorpresa del autor, en ningún momento advirtió que se tomase medida sanitaria efectiva alguna, como el aislamiento de los barrios infectos, sino que lo primero que acordó el cabildo sevillano fue la celebración de rogativas por la calamidad pública. Ante el fracaso de estas procesiones, el pueblo sevillano pidió que fuese expuesto en lo alto de la Giralda el lignum crucis, una de las reliquias más veneradas de la catedral hispalense, y que en esta seo se descubriese para su adoración una imagen del Santo Cristo. La concentración de gentes en templo y calles, «venida de todos los puntos de la ciudad, [hizo que] condensara en un foco común los hasta entonces dispersos gérmenes de la epidemia». Después las muertes se multiplicaron por diez ${ }^{18}$.

El peligro de la fiebre amarilla amenazó el país también en los años siguientes. En 1803 se detectó esta enfermedad en algunos puertos mediterráneos, como Málaga y Alicante. En Alcoi, sintiendo próxima la epidemia, fueron dispuestas las medidas habituales de control del tránsito de personas y mercaderias, estableciéndose una vigilancia especial sobre las posadas y los forasteros que en ellas se alojaban ${ }^{12}$. Fue en

17. Archivo Municipal de Alcoi, Libro de cabildos 1799-1803, cabildo del 3-X-1800, p. 107-110; «se hizo también presente la orden de veinte de setiembre illtimo (...) comprehensiva de quince capitulos para su publicación y observancia (...) a fin de precaver con ellos se propague a los pueblos de este Revno la enfermedad epidémica que causa tantos extragos en la ciudad de Cádiz y poblaciones imediatas (...) a cuvo fin se pongan sugetos que guarden y celen en las cinco entradas principales del pueblo y demás que se tengan por combeniente (sic) que no se introduzca perona alguna contra lo prevenido en el mismo bandos.

18. José Blanco White, Cartas de España, edición de Antonio Garnica, Madrid: Alianza, 1983; carta VI (Sevilla, 1801).

19. Archivo Municipal de Alcoi, Libro de cabildos 1799-1803, cabildos del 29-X-1803, p. 521-522, y del 18-XI-1803, p. 525-526; «se ha sabido que en la ciudad de Málaga se padece la enfermedad coniagiosa de fiebre anarilla, que en la ciudad de Alicante se han tomado precaliciones de resultas de un buque que llegó a su puerto con personas infestas de las quales han muerto algunas; que un patrón y tres marineros de Benidorm de esta gobernación havian fallecido en el mar viniendo de poniente (...) se hicieron comparecer a este ayuntamiento a dos vecinos de la villa de Sorban llamados el uno Marfín Lozano y el otro Bernardo Fernández Soler, los quales, preguntados sobre las noticias referidas, dixeron: que el dia veinte y dos de los corrientes salieron de, su patria, en la qual y en sus contornos es bien público que en Málaga se está padeciendo la enfermedad de fiebre amarilla, que su comunicación por otros pueblos fanto por tierra y por mar está absolutamente cortada, que dentro de aquella ciudad hay calles cerradas y que ha circulado pliego por los castillos y pueblos de la costa de Vera dando noticia y orden para que no admitan barco alguno que vaya de la parte de Malaga (...) que of $S^{w}$. Corregidor dirija las oportunas órdenes a las justicias de las villas de Villajoyosa y Benidorm. únicas de este Partido que están a la costa del mar, para que cuiden con la mayor actividad y celo de 
estas circunstancias cuando se propuso construir un cementerio fuera de la villa a causa «de los graves inconvenientes que son de temer en esta villa de enterrar los cadáveres en sus iglesias, además de ser insuficientes para la multitud de habitantes» ${ }^{20}$. En 1804 la malaria afectó gravemente la ciudad de Alicante y por ello cundió el temor en Alcoi a la extensión del contagio. Aparte de las medidas de prevención habituales, el cabildo local propuso el 15 de septiembre establecer dos lazaretos alejados de la villa, uno para enfermos en la ermita de san Cristóbal y otro de cuarentena en el santuario de la Font Roja. Dos días después se acordó celebrar rogativas para solicitar el auxilio divino ante el peligro de la epidemia. En octubre se ordenó cerrar las puertas de la villa todas las noches hasta que pasase el peligro y un mes después se prohibió la adquisición de víveres, y especialmente los embutidos, del exterior. En febrero de 1805 se consideró, al fín, extinguido el mal y por tanto se acordó celebrar unas rogativas de gracias por el cese del contagio ${ }^{21}$. Además, respecto a la cuestión del cementerio extramuros, el ayuntamiento llegó a la conclusión de que no se podía enterrar más cadáveres en los templos porque sus fosas estaban llenas y no se tenía ni siquiera otro lugar para vaciarlas. El sacristán y el sepulturero de la parroquia certificaron que, efectivamente, de las tres fosas comunes que había, dos estaban repletas y la tercera casi ${ }^{22}$. Los sucesos de la guerra del Francés atrasaron el proyecto de edificación de un cementerio extramuros, el cual no fue abierto hasta 1812. Fue ubicado, atendiendo a las recomendaciones de la superioridad, en la parte alta de la población, en el llamado Altet de la Creu, al final de la actual calle de san Vicente ${ }^{23}$.

Con la apertura del cementerio extramuros se produjeron cambios apreciables en las costumbres funerarias ${ }^{24}$. Uno de ellos fue el declive del uso de hábito como mortaja, que se agudizó además con los sucesivos intentos de supresión del clero regular instalado en Alcoi. En cuanto a la elección del lugar de sepultura, hasta 1814 prácticamente todos los testadores pedían ser enterrados en los distintos templos que había en Alcoi; los índices de elección de sepultura son mucho más elevados en esta villa que en otros lugares hasta ahora estudiados, como Málaga, Barcelona o Ruán, con un noventa por ciento ${ }^{25}$. Lógicamente, tras la apertura del cementerio extramuros, estas peticiones dejaron de aparecer en los testamentos o simplemente fueron desestimadas.

no admitir barco alguno que llegue de la parte de poniente sin hacer antes la rigurosa quarentena que correpondes.

20. Archivo Municipal de Alcoi, Libro de cabildos 1799-1803, cabildo del 12-XI1-1803, p. 534-536.

21. AMA, Libro de cabildos 1804-1807, cabildos del 15-IX-1804, p. 100-103; del 17-IX-1804, p. 106; del 24-IX-1804, p. 115-1 16; del 15-X-1804, p. 120; del 12-XI-1804, p. 126 y del 4-II- 1805, p. 167.

22. José Cortés Miralles, Crecimiento urbano de Alcoy en el siglo XIX, Valencia: Artes Gráficas Soler, 1976, p. $201-202$

23. Ibidem, p. 204. Ricard Baño, Rutes històriques i monumentals dAlcoi, p. 28.

24. Josep Lluís Santonja Cardona: «Canvis en la mentalitat religiosa a Alcoi arran la construcció del cementeri extramurs», en Congressos Jaume l. El País de les Ciutats, València: Fundació Ausiàs March, 1994.

25. Ricardo García Cárcel: «La muerte en Ia Barcelona del Antiguo Régimen», en Actas de las II jornadas de metodología histórica aplicada, II, p. 120. M. Goujard: «Échec d'une sensibilité baroque: les testaments rouennais au XVHIe. siècle», en Annales (E.S.C.), año 36, n 1, 1981, p. 36. Marion Reder Gadow, Morir en Málaga, p. 136. 